\title{
In Vitro and Human Pharmacoscintigraphic Evaluation of an Oral 5-ASA Delivery System for Colonic Release
}

Anastasia Foppoli, Alessandra Maroni*, Saliha Moutaharrik, Alice Melocchi, Lucia Zema, Luca Palugan, Matteo Cerea, Andrea Gazzaniga

Università degli Studi di Milano

Dipartimento di Scienze Farmaceutiche Sezione di Tecnologia e Legislazione Farmaceutiche "Maria Edvige Sangalli" via G. Colombo 71

20133 Milano, Italy

Corresponding author

*Alessandra Maroni

Università degli Studi di Milano

Dipartimento di Scienze Farmaceutiche

Sezione di Tecnologia e Legislazione Farmaceutiche "Maria Edvige Sangalli"

via G. Colombo 71

20133 Milano, Italy

Tel +390250324654

email: alessandra.maroni@unimi.it

In loving memory of Professor Maria Edvige Sangalli, on the $10^{\text {th }}$ anniversary of her passing 


\section{KEYWORDS}

Oral colon delivery, time-dependent release, 5-aminosalicylic acid, hydroxypropyl methylcellulose, spray-coating, pharmacoscintigraphy

\section{ABSTRACT}

5-aminosalicylic acid (5-ASA) is the most widely used drug for the treatment of ulcerative colitis. The benefits of targeted delivery of 5-ASA to the large intestine are well known, resulting in reduced systemic absorption and increased local concentrations at the disease site. In the present study, a 5ASA colon delivery system based on the time-dependent strategy, exploiting the relatively consistent small intestinal transit time (SITT), was manufactured and evaluated in vitro as well as in vivo. The system was obtained by successive spray-coating of an immediate-release tablet core with lowviscosity HPMC and Eudragit ${ }^{\circledR}$ L. The enteric film was effective in preventing release during the acidic stage of the in vitro test, while the HPMC coating brought about reproducible lag phases prior to release in phosphate buffer medium. A $\gamma$-scintigraphy investigation pointed out that, following

15 administration to fasted and fed volunteers, disintegration of the units never occurred prior to colon arrival. In all cases, a lag time preceded the appearance of the drug and its $\mathrm{N}$-acetyl metabolite in the bloodstream, which was found to correlate with the time of disintegration in a linear mode. The plasma levels of the drug and metabolite as well as their cumulative urinary recovery were relatively low with respect to those reported when 5-ASA is delivered to the small bowel. 


\section{INTRODUCTION}

5-aminosalicylic acid (5-ASA), also known as mesalazine or mesalamine, is the first-line and most widely used treatment for remission and maintenance of remission of mild-to-moderate ulcerative colitis (UC) (Feagan, 2003; Ham and Moss, 2012; Sandborn, 2008). UC is a potentially debilitating

5 chronic inflammatory pathology that, together with Crohn's disease, affects over three million people in Europe and North America, showing a currently increasing trend in developing countries of nonWestern areas (Molodecky et al., 2012; Ng et al., 2017).

Because it has been proved to act locally, selective delivery of 5-ASA to the disease site, via oral or rectal administration, is generally pursued (Friend, 2005; Perrotta et al., 2015). This enhances the

10 efficacy and tolerability associated with the therapy, by increasing the dose fraction reaching the inflamed mucosa and reducing that entering the systemic circulation due to poor colonic absorption In order to obtain effective levels of 5-ASA in the large bowel following oral intake, proper delivery strategies need to be used (Karrout et al., 2015; Qureshi and Cohen, 2005; Sardo et al., 2019). The vast majority of commercially-available 5-ASA products relate to a pH-dependent strategy (Maroni et al.,

15 2017b; Sandborn and Hanauer, 2003). The basic concept behind that is the aboral increase in the gastrointestinal $\mathrm{pH}$, which ranges from acidic values of the gastric fluid to neutral or slightly alkaline ones of the distal intestine contents. Accordingly, coated dosage forms provided with an enteric film are used, and polymers soluble at $\mathrm{pH}>6.0$ or 7.0, primarily polymethacrylates such as Eudragit ${ }^{\circledR} \mathrm{S}$ and Eudragit $^{\circledR}$ L, are generally employed as the coating agents (Maroni et al., 2013b; Palugan et al., 2015).

20 Nevertheless, it has broadly been highlighted that these coatings may not be suitable for site-selective release to the colon (Ashford et al., 1993; Ibekwe et al., 2008, 2006). Indeed, while the dissolution pH threshold of such polymers can physiologically be exceeded in the small intestine, it may fail to be reached in the proximal colon, where acidic values are often encountered particularly in active phases 
of UC (Fallingborg et al., 1993; Nugent et al., 2001). Moreover, there is large intra- and inter-patient variability in the intestinal $\mathrm{pH}$ profile. Therefore, the likelihood of both premature release and of release failure is to be accounted for. In the lack of effective and reliable targeting, mucosal levels of 5ASA may vary, thus affecting the clinical response rate (Klotz and Schwab, 2005).

5 Although no related drug products are found on the marketplace, colon delivery approaches that leverage physiological parameters other than the luminal $\mathrm{pH}$ have been proposed and extensively studied (Gazzaniga et al., 1994; McConnell et al., 2009; Pinto, 2010; Wolk et al., 2013). Among these, the time-dependent strategy exploits the small intestinal transit time (SITT) (Davis, 1985; Gazzaniga et al., 2006). It has been shown that SITT has duration of $3 \pm 1 \mathrm{~h}$ (mean \pm sd) and is relatively little influenced by variables such as the fasted/fed state of subjects, the kind of dosage forms and, in the case of solids, the size and density of the latter. In addition, because it is no inherent physiological characteristic of the colonic region, SITT would to a lesser extent undergo pathological alterations associated with UC as compared with the local $\mathrm{pH}$ and the composition of the microbiota (Bak et al., 2018).

15 Time-dependent delivery systems are generally coated dosage forms, wherein a $\mathrm{pH}$-independent coating material is responsible for a programmable lag phase prior to release (Gazzaniga et al., 2006; Maroni et al., 2013b). In order to turn time-programmed into site-selective release, the impact of unpredictable gastric residence time is to be overcome, which is commonly accomplished through the use of a gastroresistant outer coating. Furthermore, the lag phase needs to be sufficiently extended to cover the whole small intestinal transit. Taking account of the generally long-lasting transit of dosage forms in the large intestine, lag phases of 6 to $7 \mathrm{~h}$ may reasonably prevent early drug release into the proximal gastrointestinal tract while still allowing for targeted delivery to the ascending colon (Wilson, 2010). According to the nature of the inner coating polymer and the formulation of the core, the drug 
release may be deferred through a range of mechanisms (Maroni et al., 2013c). When swellable hydrophilic polymers, typically soluble cellulose derivatives, are used as coating agents, release is delayed due to their slow interaction with the aqueous gastrointestinal fluids and consequent dissolution and/or erosion in the hydrated state (Maroni et al., 2016b).

5 A previously described delivery system, provided with a functional low-viscosity HPMC layer applied by spray-coating, has been proved to fulfill the desired release behavior in vitro and in vivo, with lag phases increasing in duration as a function of the thickness of such a layer (Sangalli et al., 2001; Zema et al., 2007). Moreover, colonic breakup was highlighted by $\gamma$-scintigraphy following administration of placebo units to healthy volunteers. Various configurations of this delivery platform were proposed by using different cores (Del Curto et al., 2014, 2011, 2009; Maroni et al., 2013a) and alternative manufacturing techniques (Macchi et al., 2015; Foppoli et al., 2017; Melocchi et al., 2018; Sangalli et al., 2009; Zema et al., 2013). Particularly, in the form of coated insulin minitablets, the system brought about more than two-fold bioavailability and ten-fold pharmacological availability $v s$ a reference uncoated formulation for immediate release when administered to diabetic rats (Maroni et al., 2016a).

15 Based on the current need for effectively targeted pharmacological therapy of IBD, the aim of the present study was to manufacture, according to the above-mentioned delivery technology, an oral system for colonic release of 5-ASA, and to evaluate the relevant in vitro as well as in vivo performance. The manufacturing step involved (i) preparation of immediate-release tablet cores containing $400 \mathrm{mg}$ of the drug, (ii) application of a low-viscosity HPMC layer of approximately 750 $\mu \mathrm{m}$ in thickness, by virtue of previous in vivo studies of analogous systems (Maroni et al., 2016a; Sangalli et al., 2009, 2001), and (iii) enteric coating of the HPMC-coated units. After physicotechnological and in vitro release characterization, combined pharmacokinetic and scintigraphic investigation into the performance of the final delivery system was carried out in healthy volunteers. 


\section{MATERIALS AND METHODS}

\subsection{MATERIALS}

5-aminosalcylic acid (5-ASA, Chemi, I), povidone (Kollidon ${ }^{\circledR} 25$ BASF, D) and crospovidone Kollidon $^{\circledR}$ CL, BASF, D), glyceryl dibehenate (Compritol ${ }^{\circledR} 888$ ATO, Gattefossé, F), lactose

5 (Pharmatose DCL11 DMW, NL), samarium oxide (Sigma-Aldrich, US), hydroxypropyl methylcellulose (HPMC, Methocel $^{\circledR}$ E50, Colorcon, US; MW 65-80 kDa), polyethylene glycol (PEG 6000, Hoechst, UK), poly(methacrylic acid, methyl methacrylate) 1:1 copolymer (Eudragit ${ }^{\circledR}$ L30D, Evonik, D), triacetin and talc (Tradeco, I).

\subsubsection{Manufacturing and physico-technological characterization of the 5-ASA delivery system}

1.51 of povidone aqueous solution $(10 \% \mathrm{w} / \mathrm{v})$ was slowly added to $1.6 \mathrm{~kg}$ of 5 -ASA powder and kneaded in a high shear mixer at $100 \mathrm{rpm}$ for $5 \mathrm{~min}$ (Roto Junior 10L Zanchetta-Romaco, I). The wet mass was forced through a $250 \mu \mathrm{m}$ net sieve of an oscillating granulator (AR400 Erweka, D). The resulting granules were oven-dried at $40{ }^{\circ} \mathrm{C}$ for $20 \mathrm{~h}$ and sieve-calibrated $(500 \mu \mathrm{m}) .0 .396 \mathrm{~kg}$ of lactose, $0.072 \mathrm{~kg}$ of crospovidone, $0.032 \mathrm{~kg}$ of talc, $0.032 \mathrm{~kg}$ of glyceryl behenate, and $0.040 \mathrm{~kg}$ of samarium dioxide were added and mixed in a V-blender (Erweka, D). The mixture was tableted by a rotary machine (AR 13 Ronchi, I; concave punches diameter $11 \mathrm{~mm}$, curvature radius $9 \mathrm{~mm}$ ) set to provide adequate mechanical characteristics of the cores, so that these could withstand the subsequent coating steps while maintaining prompt disintegration properties upon exposure to aqueous media.

Tablets were checked for weight $(n=20)$, height and diameter (digital micrometer Mitutoyo, J; $n=20$ ), crushing strength (crushing tester TBH30 Erweka, D; n=10), friability (friabilometer TA3R Erweka, D) and disintegration time (three-position disintegration apparatus Advanced Products, I; $n=6$ ). The 
weight, height, diameter, crushing strength, friability and disintegration time were $555.2 \pm 2.8 \mathrm{mg}$, $6.453 \pm 0.037 \mathrm{~mm}, 11.072 \pm 0.004 \mathrm{~mm}, 81 \pm 19 \mathrm{~N},<1 \%$ and $<1 \mathrm{~min}$, respectively.

The 5-ASA tablet cores were coated in fluid bed equipment (Uniglatt, Glatt, D) using an aqueous solution of Methocel $^{\circledR}$ E50 (7.5\% w/v) and PEG $6000(0.5 \%$ w/v) under the following process

5 conditions: batch size $1 \mathrm{~kg}$, inlet air temperature $60-64{ }^{\circ} \mathrm{C}$, outlet air temperature $39-44{ }^{\circ} \mathrm{C}$, nebulizing air pressure 3.5 bar, nozzle port size $1.2 \mathrm{~mm}$. The coating level was monitored by measuring the weight and height as well as diameter (digital micrometer) of samples $(n=10)$ collected at successive time points. The coating thickness was calculated as half of the mean difference between the height and diameter of coated units and cores, respectively.

10 Coated systems having selected weight gains, in a 10-50\% range (M10, M20, M30, M40 and M50), were cross-sectioned and the thickness of the applied layer was measured on images acquired by digital microscope (Dyno-Lite Pro AM-413T, AnMo Electronics Co., TW). Thickness data were the mean of measurements performed in 8 different regions of the HPMC layer of each of 3 coated units.

Enteric coating dispersions (Eudragit ${ }^{\circledR}$ L30D 35\% w/v; Triacetin 3\% w/v, Talc 7\% w/v, deionized

15 water $55 \mathrm{w} / \mathrm{v}$ ) were applied onto HPMC-coated cores having nominal $50 \%$ weight gain to give final gastroresistant systems (GM50). The coating process was run up to approximately 3\% weight gain using the same fluid bed apparatus under the following conditions: batch size $1 \mathrm{~kg}$, inlet air temperature $60-62{ }^{\circ} \mathrm{C}$, outlet air temperature $39-41{ }^{\circ} \mathrm{C}$, nebulizing air pressure 1.5 bar, nozzle port size $1.2 \mathrm{~mm}$. Mass uniformity of the final double-coated system was assessed ( $\mathrm{CV}=0.58)$.

20 SEM photomicrographs of cross-sectioned final double-coated units were taken and used to assess the thickness of the enteric coating and confirm that of the HPMC layer. Samples were gold sputtered using a plasma evaporator under vacuum, and photomicrographs were acquired at an accelerated voltage of $10 \mathrm{kV}$ at different magnifications (Leo 1430, Carl Zeiss, CH). 


\subsubsection{In vitro evaluation}

For release testing, a three-position disintegration apparatus was used in place of a dissolution equipment to avoid adhesion of swollen HPMC layer of the coated system to the vessels, which would

5 impact on data reliability (Zema et al., 2007). Each unit was inserted into a basket-rack assembly so that only one of the 6 available tubes was occupied. The basket-rack assemblies moved in separate vessels at a constant 29 to 32 cycles/min frequency through a $55 \pm 2 \mathrm{~mm}$ distance, immersed in $800 \mathrm{ml}$ of fluid at $37 \pm 1{ }^{\circ} \mathrm{C}$, i.e. hydrochloric acid solution $\mathrm{pH} 1.2$ for $2 \mathrm{~h}$ (gastroresistant systems only) and/or phosphate buffer $\mathrm{pH} 6.8$.

10 Fluid samples were withdrawn continually for spectrophotometrical assay $(\lambda=244 \mathrm{~nm})$ at fixed time points and subsequently reintroduced into the vessel. Release tests $(n=3)$ were carried out under sink conditions, here meant as those at which the concentration of the drug was $<20 \%$ of its solubility in phosphate buffer pH 6.8 at $37^{\circ} \mathrm{C}(\sim 3.5 \mathrm{~g} / \mathrm{l})$ (Karkossa and Klein, 2018).

In vitro lag time was expressed as the time required for $10 \%$ drug release in phosphate buffer $\mathrm{pH} 6.8$

$15\left(\mathrm{t}_{10 \%}\right)$ and calculated by linear interpolation of the experimental data immediately before and after this release percentage.

\subsubsection{Pharmacoscintigraphic evaluation}

The in vivo evaluation was carried out as an open-label, single-dose study in 6 healthy male Caucasian volunteers aged 18 to 45 years, who received the test formulation (GM50) in fasted and fed conditions according to a randomized two-period crossover design (washout of 7 days). The investigation was undertaken at the U.L.B., Faculté de Médecine, Hôpital Erasme, Service des Radioisotopes (Brussels, BE). The protocol was granted approval by a registered ethics committee, in compliance with local 
regulations. The study was performed in accordance with the Declaration of Helsinki and its subsequent revisions. The enrolled subjects gave written informed consent and, prior to beginning, underwent a thorough medical examination. These controls were repeated at discharge. No medications were allowed during the study period.

5 Formulation GM50 was irradiated in a neutron flux of $2 \cdot 10^{12} \mathrm{~cm}^{-2} / \mathrm{s}$ for $4 \mathrm{~min}$, so that the stable isotope ${ }^{152} \mathrm{Sm}$ could be converted into the $\gamma$-emitting radionuclide ${ }^{153} \mathrm{Sm}$ (Wilding et al., 2001). Release testing after neutron irradiation confirmed that no alterations were brought about by such a procedure. At the time of dosing, the formulation was radiolabelled with $3.0 \mathrm{MBq}$. For each study session, $1.85 \mathrm{MBq}$ ${ }^{99 \mathrm{~m}} \mathrm{Tc}$-colloid in $100 \mathrm{ml}$ of water was also administered to outline the gastrointestinal tract.

10 On each administration day, at 8.00 a.m., all volunteers took orally a single dose of the radiolabeled formulation with $100 \mathrm{ml}$ of tap water at room temperature. In the fed administration regimen, a standard breakfast of same composition was served 30 min before intake. Standard lunch, snack and dinner were served to all volunteers at 4,8 and $12 \mathrm{~h}$ post-dose, respectively. At $24 \mathrm{~h}$ post-dose, breakfast was allowed as prescribed in the balanced standard diet the volunteers had to follow in the 3

15 days preceding administration. Neither food nor drink apart from these meals were permitted (except for water).

The subjects were placed in supine position under the collimator of the $\gamma$-camera, and images of 2 min in duration were acquired just before intake $(\mathrm{t}=0)$ and at the scheduled time points of $0.5,1,1.5,2,2.5$, $3,4,5,6,7,8,9,10,11,12$ and 24 h post-dose. Actual imaging times are reported in the Results and 20 Discussion section. Gastric emptying time (GE), colon arrival time (CA), small intestinal transit time (SITT) and time of disintegration $\left(\mathrm{t}_{\mathrm{d}}\right)$ as well as site of disintegration $\left(\mathrm{s}_{\mathrm{d}}\right)$, i.e. when and where dispersed fragments from disintegrated units were first observed, respectively, were assessed. Time of disintegration after gastric emptying $\left(\mathrm{t}_{\mathrm{d}-\mathrm{GE}}\right)$ was calculated by subtracting GE from $\mathrm{t}_{\mathrm{d}}$. 
Blood sampling was scheduled just before intake of the dosage form ( $\mathrm{t}=0)$, every hour up to $12 \mathrm{~h}$ and at $24 \mathrm{~h}$ post-dose. Actual sampling times are reported in the Results and Discussion section. Urine was also collected prior to administration, from 0 to $12 \mathrm{~h}$ and from 12 to $24 \mathrm{~h}$. 5-ASA and its metabolite Nacetyl 5-ASA (Ac5-ASA) were assayed in the plasma and urine by a HPLC validated method with

5 fluorescence detection adapted from (Fischer et al., 1981). The limit of quantitation, defined as the analyte concentration that provides a relative response with a coefficient of variation not exceeding 20 , was $5 \mathrm{ng} / \mathrm{ml}$ for both 5-ASA and Ac5-ASA in the plasma, and, in urine, $0.25 \mu \mathrm{g} / \mathrm{ml}$ for 5 -ASA and 5 $\mu \mathrm{g} / \mathrm{ml}$ for Ac5-ASA.

Lag time prior to appearance of the drug $\left(\mathrm{t}_{\operatorname{lag} 5-\mathrm{ASA}}\right)$ and of the metabolite $\left(\mathrm{t}_{\operatorname{lag} \text { Ac5-ASA }}\right)$ in the bloodstream was expressed as the time at which 5-ASA and Ac5-ASA were first assayed in the plasma.

\section{RESULTS AND DISCUSSION}

\subsection{IN VITRO EVALUATION}

15 Tablet cores containing 5-ASA underwent aqueous spray-coating with low-viscosity HPMC as previously described, in order to obtain a lag phase prior to release, according to the time-dependent approach to colon delivery (Sangalli et al., 2001). The operating parameters were preliminarily set up, and slight adjustments were progressively required due to the growing mass of the substrate. Coated formulations having nominal 10, 20, 30, 40 and $50 \%$ weight gain (codes M10, M20, M30, M40 and

20 M50) were subjected to physico-technological and release characterization. Consistent weight and coating thickness as well as a smooth surface were observed (Table I, Figures 1 and 2). A linear correlation $\left(\mathrm{R}^{2}=0.9973\right)$ was found between the weight gain of the units and the thickness of the HPMC layer (Figure 3). The pursued nominal thickness of $750 \mu \mathrm{m}$ corresponded to a weight gain of 
approximately $50 \%$. The coated systems, subjected to crushing test, were deformed without breaking at applied forces up to $300 \mathrm{~N}$. Only in the case of M10, signs of rupture were noticed.

The release profiles from uncoated cores and HPMC-coated units, obtained in phosphate buffer $\mathrm{pH} 6.8$ under sink conditions, are reported in Figure 4. A lag phase preceded the onset of 5-ASA release in all cases. By increasing the coating level, the duration of the lag phase was extended. A slow release phase due to outward drug diffusion was especially evident in the case of formulations having the greater weight gain (M40 and M50). Afterwards, release was prompt and quantitative, associated with the observed breakup of the swollen polymer layer. The relationship between the coating thickness and the duration of the lag phase, expressed as $\mathrm{t}_{10 \%}$, was found linear (Figure 5). This finding was consistent with previous ones relevant to coated systems having tableted cores of smaller size, cores of different nature (hard and soft gelatin capsules) or functional polymeric layers fabricated by different techniques (injection-molding, fused deposition modelling) (Gazzaniga et al., 2011; Maroni et al., 2017a; Sangalli et al., 2009).

Formulation M50, having coating thickness of approximately $765 \mu \mathrm{m}\left(\sim 68 \mathrm{mg} / \mathrm{cm}^{2}\right)$, was thus

15 provided with an enteric film intended to prevent interaction of the HPMC layer with the aqueous fluid in the stomach, thus overcoming the influence of highly variable gastric residence time on the intestinal site of release. Application of the enteric soluble polymer led to an increase in thickness of approximately $60 \mu \mathrm{m}\left(\sim 4.5 \mathrm{mg} / \mathrm{cm}^{2}\right)$ in the final double-coated system (GM50). Evaluated for release according to the compendial two-stage testing procedure, the gastroresistant units were proved to withstand $2 \mathrm{~h}$ in $\mathrm{HCl}$ solution. The release pattern observed after switching to phosphate buffer $\mathrm{pH} 6.8$ was consistent with that shown by the corresponding non-gastroresistant formulation, with nonsignificantly different $\mathrm{t}_{10 \%}(\mathrm{p}=0.79)$ (Figure 6). Enteric coating was thus demonstrated not to impact on the performance of the HPMC layer. 


\subsection{IN VIVO EVALUATION}

A pharmacoscintigraphic investigation was undertaken in 6 healthy male volunteers, under fasted and fed conditions. $\gamma$-scintigraphy was used to study the transit of the administered dosage forms (GM50)

5 throughout the gastrointestinal tract and the site as well as time of relevant breakup. Moreover, 5-ASA and its $\mathrm{N}$-acetyl derivative, resulting from intestinal and hepatic metabolism, were assayed in plasma samples collected within the imaging time frame in order to concurrently monitor their concentration in the systemic circulation (De Vos, 2000; Goebell et al., 1993; Klotz and Schwab, 2005). Cumulative urinary recovery of both compounds was also assessed.

10 All volunteers concluded the trial without any remarkable side effect or alteration in the main clinical parameters that could be related to the treatment. Pharmacoscintigraphic results are presented in Tables II and III as well as in Figures 7 and 8. Horizontal bars are superimposed to concentration $v s$ time curves of 5-ASA and Ac5-ASA to highlight concomitant position and disintegration of the units within the gastrointestinal tract.

15 A lag phase followed by appearance of the drug and its metabolite in the plasma was in all cases observed. As expected, 5-ASA levels turned out far lower than Ac5-ASA ones (Bondesen et al., 1988; Goebell et al., 1993). Overall, the concentrations of the drug and metabolite pointed out poor absorption, possibly consistent with distal intestinal release (Bondesen et al., 1988; Myers et al., 1987). This was in line with cumulative urinary recovery of 5-ASA and Ac5-ASA, which never exceeded $2020 \%$ of the administered dose.

Gastric residence was variable in duration, being generally shorter in the fasted regimen $(\mathrm{p}<0.05)$. Both in fasted and fed subjects, average SITT was in good agreement with previous findings, which the time-dependent colon delivery approach relies on $[21,46]$. Colon arrival was always within $5 \mathrm{~h}$ post- 
dose. Notably, in no cases disintegration occurred before the units had entered the large bowel, and residual radioactivity, ranging from 10 to $100 \%$, was still observed in the colon at $24 \mathrm{~h}$ after intake.

In 8 cases out of 12, disintegration of the units and appearance of 5-ASA and/or Ac5-ASA took place within $12 \mathrm{~h}$ after administration, the metabolite being detected either earlier than the parent drug or at

5 the same time point. In those 8 cases, the time at which disintegration was first observed after gastric emptying $\left(\mathrm{t}_{\mathrm{d}-\mathrm{GE}}\right)$ turned out to be $8.73 \pm 2.85 \mathrm{~h}$ and $7.77 \pm 3.10 \mathrm{~h}$ for fasted and fed subjects, respectively, indicating no major influence of food intake $(\mathrm{p}=0.66)$. The site of disintegration $\left(\mathrm{s}_{\mathrm{d}}\right)$, i.e. where dispersed fragments from disintegrated units were evident for the first time, was the caecum in one case $(2 \mathrm{Fa})$, the ascending colon in 5 cases $(3 \mathrm{Fa}, 4 \mathrm{Fa}, 2 \mathrm{Fe}, 3 \mathrm{Fe}, 4 \mathrm{Fe})$ and the transverse colon in the remaining 2 cases $(1 \mathrm{Fa}, 6 \mathrm{Fe})$. The time of disintegration $\left(t_{d}\right)$, i.e. when the dispersed fragments were first seen, followed (1Fa, 3Fa, 4Fa, 2Fe, 3Fe, 4Fe, 6Fe) or coincided with (2Fa) the time at which Ac5ASA was first assayed in the plasma $\left(\mathrm{t}_{\operatorname{lagAc5}-\mathrm{ASA}}\right)$, the metabolite being detected generally earlier than the parent drug because of its higher concentration. Diffusion of 5-ASA through the swollen hydrophilic polymer coating may thus have taken place before breakup of the units. The time elapsing

15 from the detection of Ac5-ASA in the plasma to that of dispersed fragments in the intestine, i.e. the difference between $t_{\operatorname{lagAc5}-\mathrm{ASA}}$ and $\mathrm{t}_{\mathrm{d}}$, was $0.81 \pm 0.56 \mathrm{~h}$ in fasted subjects and $1.27 \pm 0.59 \mathrm{~h}$ in fed ones. A good linear correlation was found between $t_{\operatorname{lagAc5-ASA}}$ and $t_{d}$ in both fasted and fed regimens, with the slope of regression lines reflecting the occurrence of metabolite absorption prior to breakup of the units (Figure 9).

20 In those 4 cases where disintegration was not observed within $12 \mathrm{~h}$ after intake $(5 \mathrm{Fa}, 6 \mathrm{Fa}, 1 \mathrm{Fe}, 5 \mathrm{Fe})$, a comprehensive evaluation of the performance of the dosage form was hindered by the lack of information between $12 \mathrm{~h}$ and $24 \mathrm{~h}$, time interval during which neither imaging nor blood sampling were scheduled. These specific cases are discussed into detail as follows. 
In subject 6Fa, 5-ASA and Ac5-ASA appeared in the plasma $11.2 \mathrm{~h}$ after intake, while disintegration was not seen in the images taken up to $12 \mathrm{~h}$. Fragments from the disintegrated unit were observed at 24 $\mathrm{h}$ post-dose in the transverse and descending colon, and residual radioactivity was $83 \%$. The plasma concentrations of drug and metabolite, along with their overall cumulative urinary recovery, were of

5 such an extent as to indicate that breakup would have occurred within the "blind" time lapse well before the 24th hour post-dose. Through the linear relationship presented in Figure 9, breakup was estimated at $12.55 \mathrm{~h}$. Based on colon arrival time, this would reasonably be consistent with the unit being positioned in the ascending and/or transverse colon.

Analogous considerations can be drawn from scintigraphic and pharmacokinetic data relevant to subject $5 \mathrm{Fe}$. In this case, $\mathrm{t}_{\mathrm{d}}$ was estimated at $13.87 \mathrm{~h}$. At $24 \mathrm{~h}$ post-dose, radioactivity in the transverse and descending colon was still 100\%.

In the same subject under fasted condition (5Fa), plasma levels of drug and metabolite as well as the disintegrated unit were detected at 24th hour only, fragments of the dosage form being positioned in the transverse and descending colon. Therefore, estimation of $t_{d}$ based on the linear regression model was not possible in this instance, and no hypothesis could accordingly be made about the site of disintegration. However, plasma concentrations and urinary recovery of 5-ASA and Ac5-ASA, relatively high and comparable with data from the same subject in the fed state, suggest breakup of the unit should be traced back to several hours before the last sampling time at $24 \mathrm{~h}$ after intake.

In subject $1 \mathrm{Fe}$, only very low 5-ASA and Ac5-ASA plasma levels, and as little as $10 \%$ of residual radioactivity in the distal part of the descending colon, were found at $24 \mathrm{~h}$. By the same time, neither the drug nor the metabolite was recovered in the urine. These results would indicate that breakup occurred just before the last time point and the unit was voided soon after disintegration. 
Overall, the administered dosage forms disintegrated and released their drug load in the large intestine, under both fasted and fed conditions of the subjects participating in the study.

\section{CONCLUSIONS}

In the present work, an oral 5-ASA delivery system aimed at time-dependent colonic release was manufactured and evaluated in vitro as well as in healthy volunteers, by $\gamma$-scintigraphy and pharmacokinetics techniques. The system encompassed an immediate-release drug-containing tablet core, a low-viscosity HPMC layer deferring the onset of release and an enteric outer coating protecting the inner formulation from contact with gastric fluid during poorly predictable stomach residence.

The expected in vitro performance was confirmed, with lag time extended as a function of the HPMC coating level. A phase of diffusive release of a relatively small percentage of the drug appeared with increasing coating thickness.

15 The imaging study showed that disintegration of the administered units was in no cases observed prior to colon arrival. Breakup mainly occurred in the caecum, ascending or transverse colon. Notably, the small intestinal transit time was proved fairly reproducible and consistent with the tenets of the timedependent formulation strategy. These findings were independent of the fasted or fed dosing regimen.

A lag phase following administration always preceded the appearance of the drug and its main metabolite in the bloodstream. An agreement was found between this lag time and the onset of disintegration of the units. 5-ASA and Ac5-ASA were generally detected approximately $1 \mathrm{~h}$ before breakup could be observed, which may reflect the diffusive release phase noticed in the in vitro study. After the lag phase, the concentrations of drug and metabolite reached in the plasma were relatively 
low as compared with data obtained following delivery of the drug to more proximal regions of the gut. This was consistent with the mean cumulative urinary recovery of 5-ASA and Ac5-ASA over $24 \mathrm{~h}$ that was below $10 \%$ of the drug dosed.

On average, the time taken for the dosage form to disintegrate after emptying from the stomach, where

5 swelling of the functional HPMC coating was prevented by the gastroresistant film, turned out slightly longer than should in principle be pursued according to the time-dependent colon delivery approach. However, the results obtained were mostly satisfactory in terms of large intestinal targeting. Therefore, though with due caution in view of the need for avoiding early release into the small bowel, formulation changes could be implemented to possibly shorten the in vivo lag time, thus offering better chances of drug delivery into the proximal colon and reducing the risk of release failure.

\section{REFERENCES}

15 Ashford, M., Fell, J.T., Attwood, D., Sharma, H., Woodhead, P.J., 1993. An in vivo investigation into the suitability of $\mathrm{pH}$ dependent polymers for colonic targeting. Int. J. Pharm. 95, 193-199. https://doi.org/10.1016/0378-5173(93)90406-6

Bak, A., Ashford, M., Brayden, D.J., 2018. Local delivery of macromolecules to treat diseases associated with the colon. Adv. Drug Deliv. Rev. 136-137, 2-27. https://doi.org/10.1016/j.addr.2018.10.009

Bondesen, S., Schou, J., Pedersen, V., Rafiolsadat, Z., Hansen, S., Hvidberg, E., 1988. Absorption of 5- aminosalicylic acid from colon and rectum. Br. J. Clin. Pharmacol. 25, 269-272. https://doi.org/10.1111/j.1365-2125.1988.tb03301.x 
Davis, S.S., 1985. The design and evaluation of controlled release systems for the gastrointestinal tract. J. Control. Release 2, 27-38. https://doi.org/10.1016/0168-3659(85)90030-6

Davis, S.S., Hardy, J.G., Fara, J.W., 1986. Transit of pharmaceutical dosage forms through the small intestine. Gut 27, 886-892. https://doi.org/10.1136/gut.27.8.886

5 De Vos, M., 2000. Clinical pharmacokinetics of slow release mesalazine. Clin. Pharmacokinet. 39, 8597. https://doi.org/10.2165/00003088-200039020-00001

Del Curto, M.D., Maroni, A., Foppoli, A., Zema, L., Gazzaniga, A., Sangalli, M.E., 2009. Preparation and evaluation of an oral delivery system for time-dependent colon release of insulin and selected protease inhibitor and absorption enhancer compounds. J. Pharm. Sci. 98, 4661-4669. https://doi.org/10.1002/jps.21761

Del Curto, M.D., Maroni, A., Palugan, L., Zema, L., Gazzaniga, A., Sangalli, M.E., 2011. Oral delivery system for two-pulse colonic release of protein drugs and protease inhibitor/absorption enhancer compounds. J. Pharm. Sci. 100, 3251-3259. https://doi.org/10.1002/jps.22560

Del Curto, M.D., Palugan, L., Foppoli, A., Zema, L., Gazzaniga, A., Maroni, A., 2014. Erodible timedependent colon delivery systems with improved efficiency in delaying the onset of drug release. J. Pharm. Sci. 103, 3585-3593. https://doi.org/10.1002/jps.24150

Fallingborg, J., Christensen, L.A., Jacobsen, B.A., Rasmussen, S.N., 1993. Very low intraluminal colonic pH in patients with active ulcerative colitis. Dig. Dis. Sci. 38, 1989-1993. https://doi.org/10.1007/BF01297074

20 Feagan, B., 2003. Maintenance therapy for inflammatory bowel disease. Am. J. Gastroenterol. 98, S6S17. https://doi.org/10.1016/j.amjgastroenterol.2003.11.002

Fischer, C., Maier, K., Klotz, U., 1981. Simplified high-performance liquid chromatographic method for 5-amino-salicylic acid in plasma and urine. J. Chromatogr. B Biomed. Sci. Appl. 225, 498- 
503. https://doi.org/10.1016/S0378-4347(00)80303-5

Foppoli, A.A., Maroni, A., Cerea, M., Zema, L., Gazzaniga, A., 2017. Dry coating of solid dosage forms: an overview of processes and applications. Drug Dev. Ind. Pharm. 43, 1919-1931. https://doi.org/10.1080/03639045.2017.1355923

5 Friend, D.R., 2005. New oral delivery systems for treatment of inflammatory bowel disease. Adv. Drug Deliv. Rev. 57, 247-265. https://doi.org/10.1016/j.addr.2004.08.011

Gazzaniga, A., Cerea, M., Cozzi, A., Foppoli, A., Maroni, A., Zema, L., 2011. A novel injectionmolded capsular device for oral pulsatile delivery based on swellable/erodible polymers. AAPS PharmSciTech 12, 295-303. https://doi.org/10.1208/s12249-011-9581-6

10 Gazzaniga, A., Giordano, F., Sangalli, M.E., Zema, L., 1994. Oral colon-specific drug delivery: Design strategies. STP Pharma Prat. 4, 336-343.

Gazzaniga, A., Maroni, A., Sangalli, M.E., Zema, L., 2006. Time-controlled oral delivery systems for colon targeting. Expert Opin. Drug Deliv. 3, 583-597. https://doi.org/10.1517/17425247.3.5.583

Goebell, H., Klotz, U., Nehlsen, B., Layer, P., 1993. Oroileal transit of slow release 5-aminosalicylic acid. Gut 34, 669-675. https://doi.org/10.1136/gut.34.5.669

Ham, M., Moss, A.C., 2012. Mesalamine in the treatment and maintenance of remission of ulcerative colitis. Expert Rev. Clin. Pharmacol. 5, 113-123. https://doi.org/10.1586/ecp.12.2

Ibekwe, V.C., Fadda, H.M., Mcconnell, E.L., Khela, M.K., Evans, D.F., Basit, A.W., 2008. Interplay Between Intestinal $\mathrm{pH}$, Transit Time and Feed Status on the In Vivo Performance of $\mathrm{pH}$ Responsive Ileo-Colonic Release Systems. Pharm. Res. 25, 1828-1835. https://doi.org/10.1007/s11095-008-9580-9

Ibekwe, V.C., Liu, F., Fadda, H.M., Khela, M.K., Evans, D.F., Parsons, G.E., Basit, A.W., 2006. An Investigation into the In Vivo Performance Variability of $\mathrm{pH}$ Responsive Polymers for Ileo- 
Colonic Drug Delivery Using Gamma Scintigraphy in Humans. J. Pharm. Sci. 95, 2760-2766. https://doi.org/10.1002/jps.20742

Karkossa, F., Klein, S., 2018. A Biopredictive In Vitro Comparison of Oral Locally Acting Mesalazine Formulations by a Novel Dissolution Model for Assessing Intraluminal Drug Release in Individual

Subjects. J. Pharm. Sci. 107, 1680-1689. https://doi.org/10.1016/j.xphs.2018.02.016

Karrout, Y., Dubuquoy, L., Piveteau, C., Siepmann, F., Moussa, E., Wils, D., Beghyn, T., Neut, C., Flament, M.P., Guerin-Deremaux, L., Dubreuil, L., Deprez, B., Desreumaux, P., Siepmann, J., 2015. In vivo efficacy of microbiota-sensitive coatings for colon targeting: A promising tool for IBD therapy. J. Control. Release 197, 121-130. https://doi.org/10.1016/j.jconrel.2014.11.006

Klotz, U., Schwab, M., 2005. Topical delivery of therapeutic agents in the treatment of inflammatory bowel disease. Adv. Drug Deliv. Rev. 57, 267-279. https://doi.org/10.1016/j.addr.2004.08.007

Macchi, E., Zema, L., Maroni, A., Gazzaniga, A., Felton, L.A., 2015. Enteric-coating of pulsatilerelease HPC capsules prepared by injection molding. Eur. J. Pharm. Sci. 70, 1-11. https://doi.org/10.1016/j.ejps.2014.12.020

15 Maroni, A., Del Curto, M.D., Cerea, M., Zema, L., Foppoli, A., Gazzaniga, A., 2013a. Polymeric coatings for a multiple-unit pulsatile delivery system: Preliminary study on free and applied films. Int. J. Pharm. 440, 256-263. https://doi.org/10.1016/j.ijpharm.2012.05.075

Maroni, A., Del Curto, M.D., Salmaso, S., Zema, L., Melocchi, A., Caliceti, P., Gazzaniga, A., $2016 a$. In vitro and in vivo evaluation of an oral multiple-unit formulation for colonic delivery of insulin. Eur. J. Pharm. Biopharm. 108, 76-82. https://doi.org/10.1016/j.ejpb.2016.08.002

Maroni, A., Del Curto, M.D., Zema, L., Foppoli, A., Gazzaniga, A., 2013b. Film coatings for oral colon delivery. Int. J. Pharm. https://doi.org/10.1016/j.ijpharm.2013.05.043

Maroni, A., Melocchi, A., Parietti, F., Foppoli, A., Zema, L., Gazzaniga, A., 2017a. 3D printed multi- 
compartment capsular devices for two-pulse oral drug delivery. J. Control. Release 268, 10-18. https://doi.org/10.1016/j.jconrel.2017.10.008

Maroni, A., Moutaharrik, S., Zema, L., Gazzaniga, A., 2017b. Enteric coatings for colonic drug delivery: state of the art. Expert Opin. Drug Deliv. 14, 1027-1029. https://doi.org/10.1080/17425247.2017.1360864

Maroni, A., Zema, L., Cerea, M., Foppoli, A., Palugan, L., Gazzaniga, A., 2016b. Erodible drug delivery systems for time-controlled release into the gastrointestinal tract. J. Drug Deliv. Sci. Technol. 32, 229-235. https://doi.org/10.1016/j.jddst.2015.10.001

Maroni, A., Zema, L., Loreti, G., Palugan, L., Gazzaniga, A., 2013c. Film coatings for oral pulsatile release. Int. J. Pharm. 457, 362-371. https://doi.org/10.1016/j.ijpharm.2013.03.010

McConnell, E.L., Liu, F., Basit, A.W., 2009. Colonic treatments and targets : issues and opportunities. J. Drug Target. 17, 335-363. https://doi.org/10.1080/10611860902839502

Melocchi, A., Parietti, F., Maccagnan, S., Ortenzi, M.A., Antenucci, S., Briatico-Vangosa, F., Maroni, A., Gazzaniga, A., Zema, L., 2018. Industrial Development of a 3D-Printed Nutraceutical Delivery Platform in the Form of a Multicompartment HPC Capsule. AAPS PharmSciTech 19, 3343-3354. https://doi.org/10.1208/s12249-018-1029-9

Molodecky, N.A., Soon, I.N.G.S., Rabi, D.M., Ghali, W.A., Ferris, M., Chernoff, G., Benchimol, E.I., Panaccione, R., Ghosh, S., Barkema, H.W., Kaplan, G.G., 2012. Increasing Incidence and Prevalence of the Inflammatory Bowel Diseases. J. Clin. Gastroenterol. 142, 46-54. https://doi.org/10.1053/j.gastro.2011.10.001

Myers, B., Evans, D.N.W., Rhodes, J., Hughes, B.R., Lee, M.G., Richens, A., Richards, D., 1987. Metabolism and urinary excretion of 5-amino salicylic acid in healthy volunteers when given intravenously or released for absorption at different sites in the gastrointestinal tract. Gut 28, 196- 
200. https://doi.org/10.1136/gut.28.2.196

Ng, S.C., Shi, H.Y., Hamidi, N., Underwood, F.E., Tang, W., Benchimol, Eric I Panaccione, R., Ghosh, S., Wu, J.C.Y., Chan, F.K.L., Sung, J.J.Y., Kaplan, G.G., 2017. Worldwide incidence and prevalence of inflammatory bowel disease in the 21 st century: a systematic review of populationbased studies. Lancet 390, 2769-2778. https://doi.org/10.1016/s0140-6736(17)32448-0

Nugent, S.G., Kumar, D., Rampton, D.S., Evans, D.F., 2001. Intestinal luminal pH in inflammatory bowel disease: possible determinants and implications for therapy with aminosalicylates and other drugs. Gut 48, 571-577. https://doi.org/10.1136/gut.48.4.571

Palugan, L., Cerea, M., Zema, L., Gazzaniga, A., Maroni, A., 2015. Coated pellets for oral colon delivery. J. Drug Deliv. Sci. Technol. 25, 1-15.

Perrotta, C., Pellegrino, P., Moroni, E., Palma, C. De, Cervia, D., Danelli, P., Clementi, E., 2015. FiveAminosalicylic Acid : An Update for the Reappraisal of an Old Drug. Gastroenterol. Res. Pract. 2015, 1-9. https://doi.org/10.1155/2015/456895

Pinto, J.F., 2010. Site-specific drug delivery systems within the gastro-intestinal tract : From the mouth to the colon. Int. J. Pharm. 395, 44-52. https://doi.org/10.1016/j.ijpharm.2010.05.003

Qureshi, A.I., Cohen, R.D., 2005. Mesalamine delivery systems : do they really make much difference? Adv. Drug Deliv. Rev. 57, 281-302. https://doi.org/10.1016/j.addr.2004.08.008

Sandborn, W.J., 2008. Oral 5-ASA Therapy in Ulcerative Colitis What are the Implications of the New Formulations? J. Clin. Gastroenterol. 42, 338-344. https://doi.org/10.1097/MCG.0b013e3181595b56

Sandborn, W.J.N., Hanauer, S.B., 2003. Systematic review : the pharmacokinetic profiles of oral mesalazine formulations and mesalazine pro-drugs used in the management of ulcerative colitis. Aliment. Pharmacol. Ther. 17, 29-42. https://doi.org/10.1046/j.0269-2813.2003.01408.x 
Sangalli, M.E., Maroni, A., Zema, L., Busetti, C., Giordano, F., Gazzaniga, A., 2001. In vitro and in vivo evaluation of an oral system for time and/or site-specific drug delivery. J. Control. Release 73, 103-110. https://doi.org/10.1016/S0168-3659(01)00291-7

Sangalli, M.E., Maroni, A., Zema, L., Cerea, M., Gazzaniga, A., 2009. Chronotopic ${ }^{\mathrm{TM}}$ Technology, in: Youan, B.B.C. (Ed.), Chronopharmaceutics: Science and Technology for Biological RhythmGuided Therapy and Prevention of Diseases. John Wiley \& Sons, Inc., Hoboken, NJ, pp. 145-163. https://doi.org/10.1002/9780470498392.ch6

Sardo, H.S., Saremnejad, F., Bagheri, S., Akhgari, A., 2019. A review on 5-aminosalicylic acid colontargeted oral drug delivery systems 558, 367-379. https://doi.org/10.1016/j.ijpharm.2019.01.022

Wilding, I.R., Coupe, A.J., Davis, S.S., 2001. The role of $\gamma$-scintigraphy in oral drug delivery. Adv. Drug Deliv. Rev. 46, 103-124. https://doi.org/10.1016/S0169-409X(00)00135-6

Wilson, C.G., 2010. The transit of dosage forms through the colon. Int. J. Pharm. 395, 17-25. https://doi.org/10.1016/j.ijpharm.2010.04.044

Wolk, O., Epstein, S., Ioffe-dahan, V., Ben-shabat, S., Dahan Arik, 2013. New targeting strategies in drug therapy of inflammatory bowel disease : mechanistic approaches and opportuni. Expert Opin. Drug Deliv. 10, 1275-1286. https://doi.org/10.1517/17425247.2013.800480

Zema, L., Loreti, G., Macchi, E., Foppoli, A., Maroni, A., Gazzaniga, A., 2013. Injection-molded capsular device for oral pulsatile release: Development of a novel mold. J. Pharm. Sci. 102, 489499. https://doi.org/10.1002/jps.23371

20 Zema, L., Maroni, A., Foppoli, A., Palugan, L., Sangalli, M., Gazzaniga, A., 2007. Different HPMC viscosity grades as coating agents for an oral time and/or site-controlled delivery system: An investigation into the mechanisms governing drug release. J. Pharm. Sci. 96, 1527-1536. https://doi.org/10.1002/jps.20802 


\section{FIGURE CAPTIONS}

Fig. 1. Photographs of uncoated cores and HPMC-coated systems having increasing coating level.

5 Fig. 2. SEM photomicrograph of the cross-section of a final double-coated system (GM50).

Fig. 3. Relationship between weight gain and HPMC coating thickness.

Fig. 4. Release profiles of 5-ASA from uncoated cores and HPMC-coated systems having increasing coating level (phosphate buffer $\mathrm{pH}$ 6.8).

Fig. 5. Relationship between HPMC coating thickness and 5-ASA in vitro lag time $\left(\mathrm{t}_{10 \%}\right)$.

15 Fig. 6. Release profile of 5-ASA from the final double-coated system (GM50).

Fig. 7. 5-ASA $(\square)$ and Ac5-ASA $(\Delta)$ plasma concentrations $v s$ time profiles following administration of the final double-coated system (GM50) to fasted volunteers (the dashed portion of the curves indicates the 12-24 h time frame during which no experimental data were collected and does not reflect the actual

20 time course of concentration). Red, yellow and green bars (bottom) indicate gastric, small intestinal and colonic residence, respectively; the blue bar (top) indicates disintegration.

Fig. 8. 5-ASA $(\square)$ and Ac5-ASA $(\Delta)$ plasma concentrations vs time profiles following administration of the final double-coated system (GM50) to fed volunteers (the dashed portion of the curves indicates the 
12-24 h time frame during which no experimental data were collected and does not reflect the actual time course of concentration). Red, yellow and green lines (bottom) indicate gastric, small intestinal and colonic residence, respectively; the blue line (top) indicates disintegration.

5 Fig. 9. Relationship between Ac5-ASA in vivo lag time ( $\left.\mathrm{t}_{\text {lagAc5-ASA }}\right)$ and time of disintegration $\left(\mathrm{t}_{\mathrm{d}}\right)$. 
Table I. Weight, weight gain and coating thickness data relevant to uncoated cores and HPMC-coated systems

\begin{tabular}{|c|c|c|c|}
\hline Formulation & $\begin{array}{c}\text { Weight }(m g) \\
\text { Mean } \pm \text { sd }\end{array}$ & Weight gain $(\%)$ & $\begin{array}{c}\text { Coating thickness } \\
\text { Mean } \pm \text { sd }\end{array}$ \\
\hline Uncoated core & $555.2 \pm 2.8$ & - & - \\
M10 & $615.2 \pm 5.4$ & 10.8 & $159.5 \pm 17.6$ \\
M20 & $669.0 \pm 5.8$ & 20.5 & $306.8 \pm 33.1$ \\
M30 & $720.1 \pm 5.3$ & 29.7 & $453.4 \pm 35.6$ \\
M40 & $782.8 \pm 5.0$ & 41.0 & $633.9 \pm 31.5$ \\
M50 & $838.5 \pm 4.7$ & 51.0 & $764.8 \pm 33.4$ \\
\hline
\end{tabular}

*measured by digital microscope 
Table II. Scintigraphic data under fasted and fed conditions

\begin{tabular}{|c|c|c|c|c|c|c|}
\hline \multicolumn{1}{|c|}{} & \multicolumn{7}{|c|}{ FASTED CONDITION } \\
\hline Subject & $\begin{array}{c}\text { Gastric } \\
\text { emptying } \\
\text { time } \\
\text { GE (h) }\end{array}$ & $\begin{array}{c}\text { Small } \\
\text { intestinal } \\
\text { transit time } \\
\text { SITT (h) }\end{array}$ & $\begin{array}{c}\text { Colon } \\
\text { arrival time } \\
\text { CA (h) }\end{array}$ & $\begin{array}{c}\text { Time of } \\
\text { disintegration } \\
\mathrm{t}_{\mathrm{d}}(\mathrm{h})\end{array}$ & $\begin{array}{c}\text { Time of } \\
\text { disintegration after } \\
\text { gastric emptying } \\
\mathrm{t}_{\mathrm{d}-\mathrm{GE}}(\mathrm{h})\end{array}$ & $\begin{array}{c}\text { Site of } \\
\text { disintegration } \\
\mathrm{s}_{\mathrm{d}}\end{array}$ \\
\hline 1 & 1.75 & 3.00 & 4.75 & 12.00 & 10.25 & $\mathrm{TC}$ \\
2 & 0.33 & 4.50 & 4.83 & 4.83 & 4.50 & $\mathrm{C}$ \\
3 & 0.42 & 1.50 & 1.92 & 11.00 & 10.58 & $\mathrm{AC}$ \\
5 & 0.42 & 4.58 & 5.00 & 10.00 & 9.58 & AC \\
6 & 0.58 & 4.50 & 5.08 & $\#$ & $\#$ \\
\hline Mean & 0.58 & 1.59 & 2.17 & $\#(12.55)$ & $\#$ \\
sd & 0.68 & 3.28 & 3.96 & 9.46 & 8.73 & $\#$ \\
\hline
\end{tabular}

\begin{tabular}{|c|c|c|c|c|c|c|}
\hline \multicolumn{7}{|c|}{ FED CONDITION } \\
\hline Subject & $\begin{array}{l}\text { Gastric } \\
\text { emptying } \\
\text { time } \\
\text { GE }(\mathrm{h})\end{array}$ & $\begin{array}{l}\text { Small } \\
\text { intestinal } \\
\text { transit time } \\
\text { SITT (h) }\end{array}$ & $\begin{array}{l}\text { Colon } \\
\text { arrival time } \\
\text { CA (h) }\end{array}$ & $\begin{array}{c}\text { Time of } \\
\text { disintegration } \\
t_{d}(h)\end{array}$ & $\begin{array}{c}\text { Time of } \\
\text { disintegration after } \\
\text { gastric emptying } \\
\mathrm{t}_{\mathrm{d}-\mathrm{GE}}(\mathrm{h})\end{array}$ & $\begin{array}{c}\text { Site of } \\
\text { disintegration } \\
\mathrm{s}_{\mathrm{d}}\end{array}$ \\
\hline 1 & 1.83 & 1.92 & 3.75 & \# & \# & $\#$ \\
\hline 2 & 2.33 & 2.50 & 4.83 & 5.83 & 3.50 & $\mathrm{AC}$ \\
\hline 3 & 1.41 & 3.51 & 4.92 & 8.92 & 7.51 & $\mathrm{AC}$ \\
\hline 4 & 2.50 & 2.50 & 5.00 & 12.90 & 10.40 & $\mathrm{AC}$ \\
\hline 5 & 1.92 & 3.00 & 4.92 & $\#_{(13.87)}$ & $\#_{(11.95)}$ & \# \\
\hline 6 & 0.58 & 3.59 & 4.17 & 10.25 & 9.67 & $\mathrm{TC}$ \\
\hline Mean & 1.76 & 2.84 & 4.60 & 9.48 & 7.77 & \\
\hline sd & 0.70 & 0.65 & 0.51 & 2.94 & 3.10 & \\
\hline
\end{tabular}

Caecum (C), ascending colon (AC), transverse colon (TC).

Time $\left(\mathrm{t}_{\mathrm{d}}\right)$ and site $\left(\mathrm{s}_{\mathrm{d}}\right)$ of disintegration refer to when and where dispersed fragments of units were first observed

\# Definite time and anatomical position of disintegration could not experimentally be assessed since dispersed fragments were seen at $24 \mathrm{~h}$ only. Disintegration occurred between 12 and $24 \mathrm{~h}$ in the colon. Times of disintegration that could be estimated on the basis of the correlation in Figure 9 are in brackets. 
Table III. Pharmacokinetic data under fasted and fed conditions

\begin{tabular}{|c|c|c|c|c|c|c|}
\hline \multicolumn{7}{|c|}{ FASTED CONDITION } \\
\hline \multirow{2}{*}{ Subject } & \multirow{2}{*}{$\begin{array}{c}\text { 5-ASA } \\
\text { lag time } \\
\mathrm{t}_{\text {lag5-ASA }}(\mathrm{h})\end{array}$} & \multirow{2}{*}{$\begin{array}{l}\text { Ac5-ASA } \\
\text { lag time } \\
\mathrm{t}_{\text {lagAc5-ASA }}(\mathrm{h})\end{array}$} & \multicolumn{2}{|c|}{$\begin{array}{l}\text { 5-ASA cumulative } \\
\text { urinary recovery }(\mathrm{mg})\end{array}$} & \multicolumn{2}{|c|}{$\begin{array}{l}\text { Ac5-ASA cumulative } \\
\text { urinary recovery }(\mathrm{mg})\end{array}$} \\
\hline & & & $0-12 \mathrm{~h}$ & $0-24 \mathrm{~h}$ & $0-12 \mathrm{~h}$ & $0-24 \mathrm{~h}$ \\
\hline 1 & 11.70 & 10.70 & 0.00 & 0.64 & 0.00 & 29.36 \\
\hline 2 & 5.83 & 4.83 & 0.87 & 2.58 & 24.75 & 83.63 \\
\hline 3 & 11.00 & 10.00 & 0.00 & 0.69 & 0.00 & 17.77 \\
\hline 4 & 11.00 & 9.07 & 0.00 & 0.68 & 0.00 & 19.04 \\
\hline 5 & $\S$ & $\S$ & 0.00 & 1.62 & 0.00 & 34.02 \\
\hline 6 & 11.20 & 11.20 & 0.00 & 1.12 & 0.00 & 25.18 \\
\hline Mean & 10.15 & 9.16 & 0.15 & 1.22 & 4.13 & 34.83 \\
\hline sd & 2.43 & 2.55 & 0.36 & 0.77 & 10.10 & 24.68 \\
\hline
\end{tabular}

\begin{tabular}{|c|c|c|c|c|c|c|}
\hline \multicolumn{7}{|c|}{ FED CONDITION } \\
\hline \multirow{2}{*}{ Subject } & \multirow{2}{*}{$\begin{array}{c}\text { 5-ASA } \\
\text { lag time } \\
\mathrm{t}_{\text {lag5-ASA }}(\mathrm{h})\end{array}$} & \multirow{2}{*}{$\begin{array}{l}\text { Ac5-ASA } \\
\text { lag time } \\
\mathrm{t}_{\text {lagAc5-ASA }}(\mathrm{h})\end{array}$} & \multicolumn{2}{|c|}{$\begin{array}{l}\text { 5-ASA cumulative } \\
\text { urinary recovery }(\mathrm{mg})\end{array}$} & \multicolumn{2}{|c|}{$\begin{array}{l}\text { Ac5-ASA cumulative } \\
\text { urinary recovery }(\mathrm{mg})\end{array}$} \\
\hline & & & $0-12 \mathrm{~h}$ & $0-24 \mathrm{~h}$ & $0-12 \mathrm{~h}$ & $0-24 \mathrm{~h}$ \\
\hline 1 & $\S$ & $\S$ & 0.00 & 0.00 & 0.00 & 0.00 \\
\hline 2 & 5.20 & 5.20 & 0.00 & 0.59 & 25.99 & 47.99 \\
\hline 3 & 8.03 & 7.30 & 0.35 & 0.65 & 6.57 & 14.72 \\
\hline 4 & 12.10 & 11.00 & 0.00 & 1.19 & 0.00 & 27.45 \\
\hline 5 & 12.00 & 12.00 & 0.00 & 1.15 & 0.00 & 26.56 \\
\hline 6 & 9.32 & 9.32 & 0.00 & 1.67 & 0.00 & 68.5 \\
\hline Mean & 9.33 & 8.96 & 0.06 & 0.88 & 5.43 & 30.87 \\
\hline sd & 2.90 & 2.76 & 0.14 & 0.58 & 10.41 & 24.30 \\
\hline
\end{tabular}

$\S$ Definite time of appearance of 5-ASA and Ac5-ASA in plasma could not experimentally be assessed since these were assayed at 24 h only. The appearance of drug and metabolite occurred between 12 and $24 \mathrm{~h}$. 


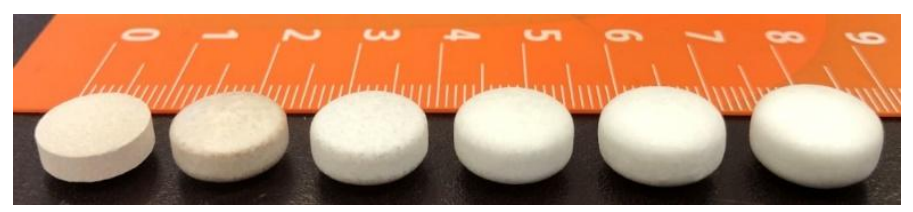

Fig. 1. Photographs of uncoated cores and HPMC-coated systems having increasing coating level (ruler scale in $\mathrm{cm}$ ).

Figure 1 Foppoli et al revised 
Figure 2 Foppoli et al revised

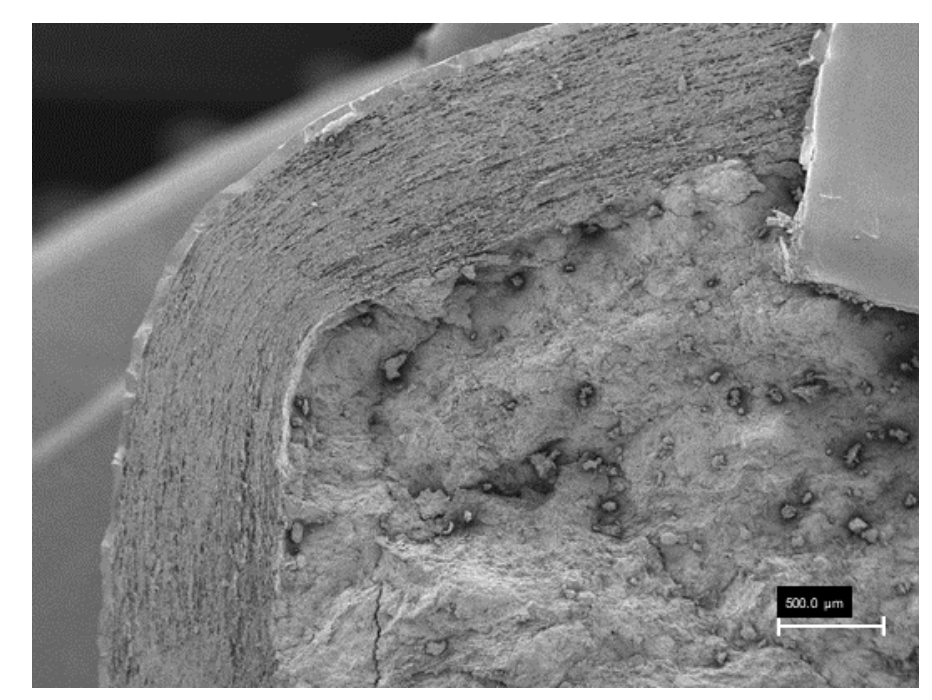

Fig. 2. SEM photomicrograph of the cross-section of a final double-coated system (GM50). 
Figure 3, Foppoli et al

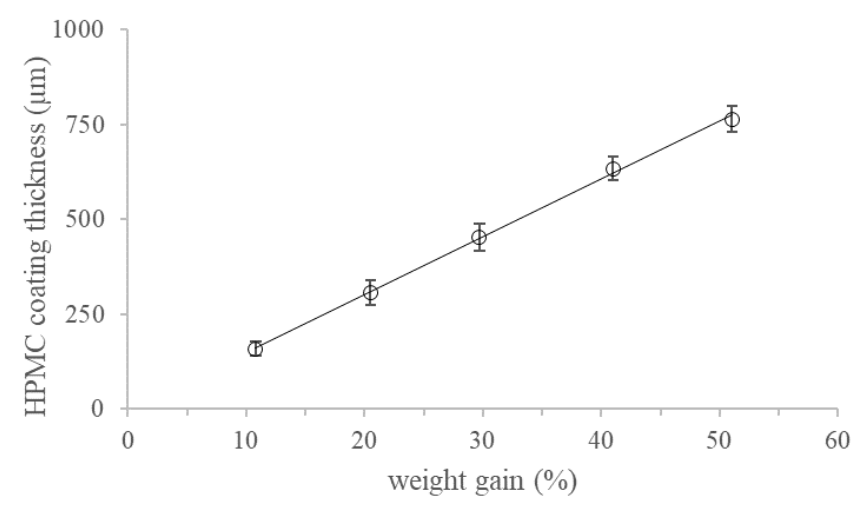

Fig. 3. Relationship between weight gain and HPMC coating thickness. 
Figure 4 Foppoli et al

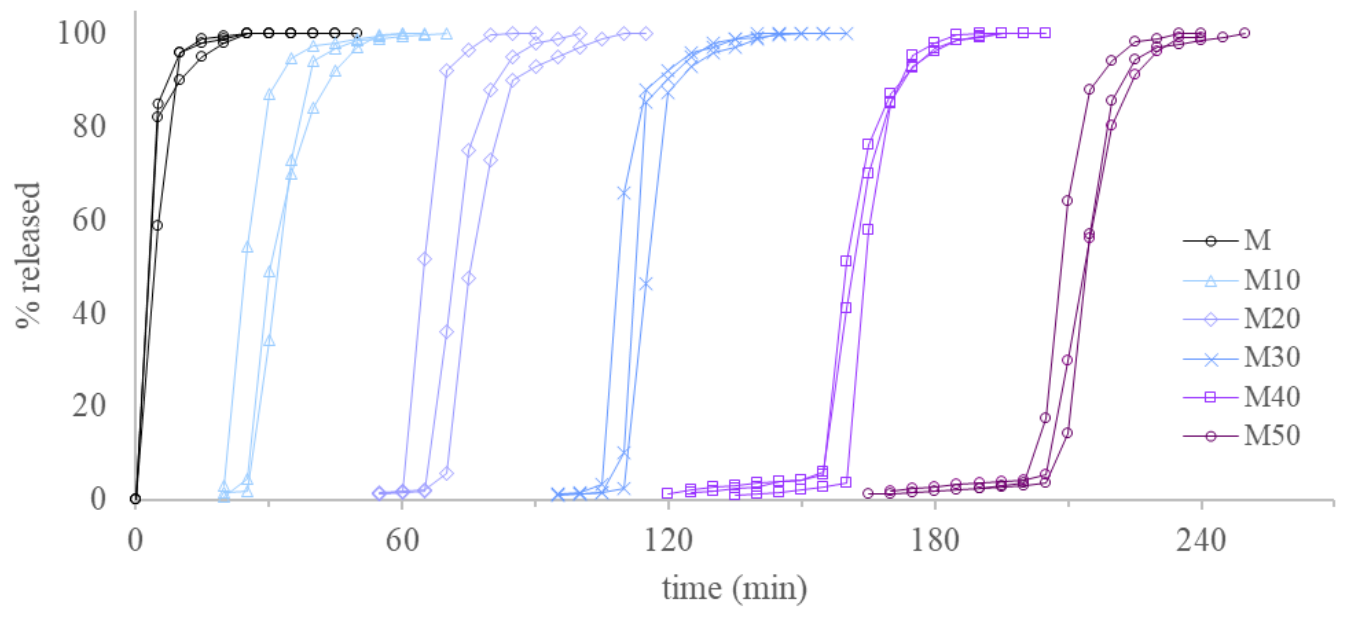

Fig. 4. Release profiles of 5-ASA from uncoated cores and HPMC-coated systems having increasing coating level (phosphate buffer $\mathrm{pH}$ 6.8). 
Figure 5, Foppoli et al

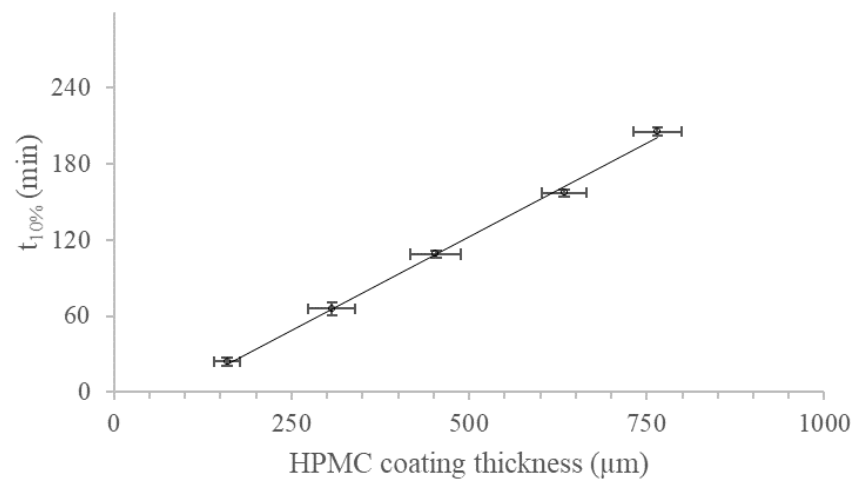

Fig. 5. Relationship between HPMC coating thickness and 5-ASA in vitro lag time $\left(\mathrm{t}_{10 \%}\right)$. 
Figure 6 Foppoli et al revised

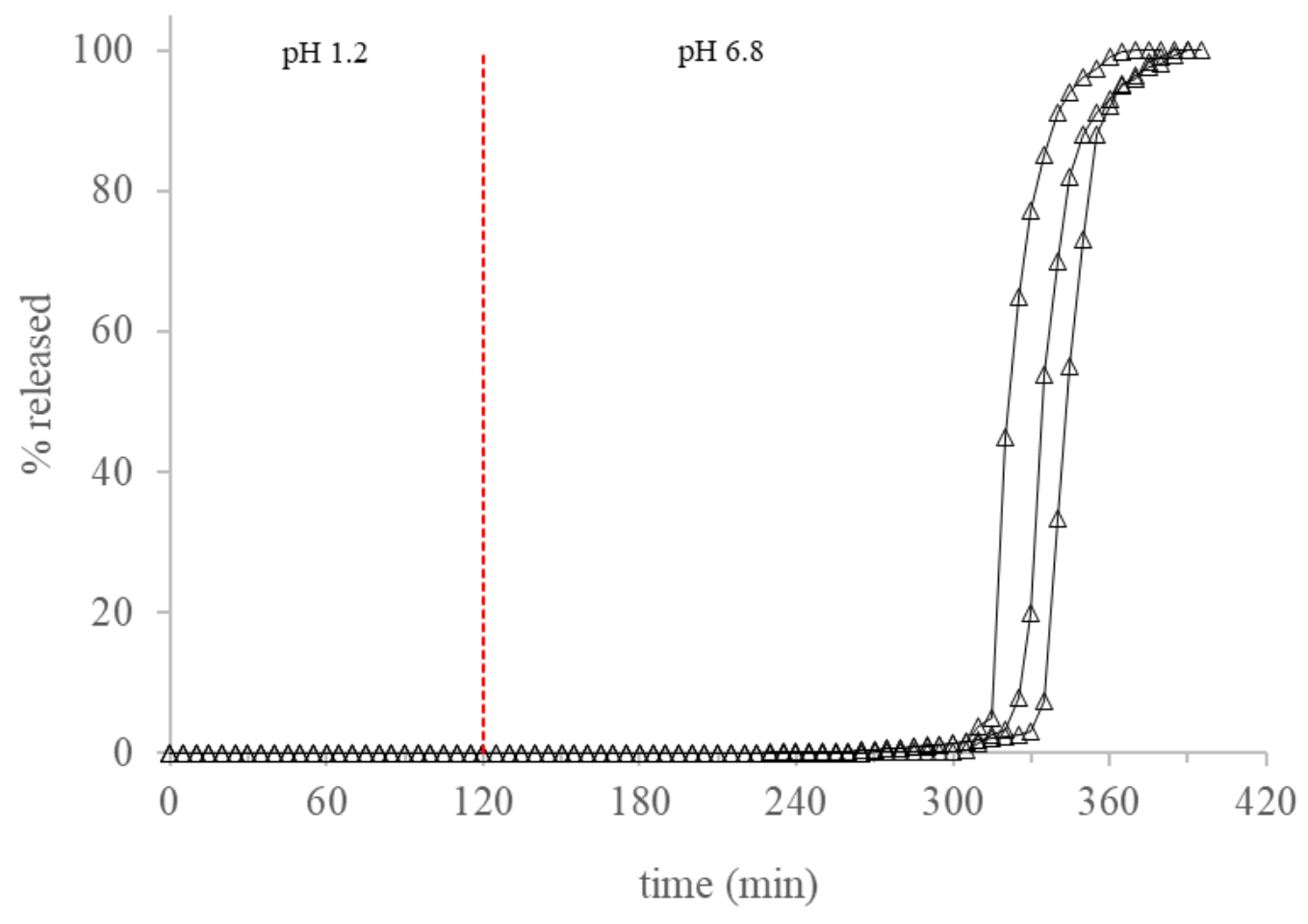

Fig. 6. Release profile of 5-ASA from the final double-coated system (GM50). 

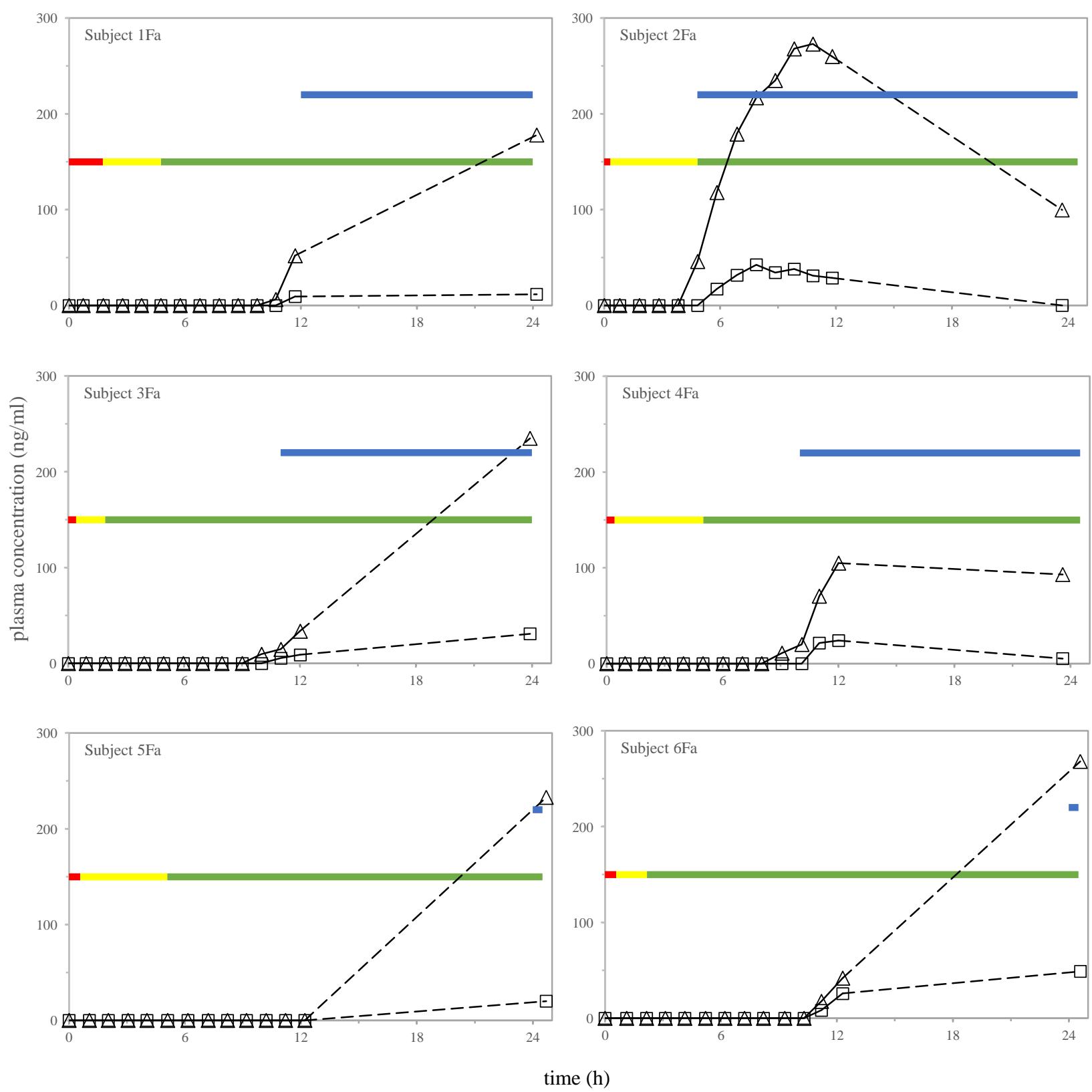

Fig. 7. 5-ASA ( $\square)$ and Ac5-ASA ( $\Delta)$ plasma concentrations $v s$ time profiles following administration of the final double-coated system (GM50) to fasted volunteers (the dashed portion of the curves indicates the 12-24 h time frame during which no experimental data were collected and does not reflect the actual time course of concentration). Red, yellow and green bars (bottom) indicate gastric, small intestinal and colonic residence, respectively; the blue bar (top) indicates disintegration. 

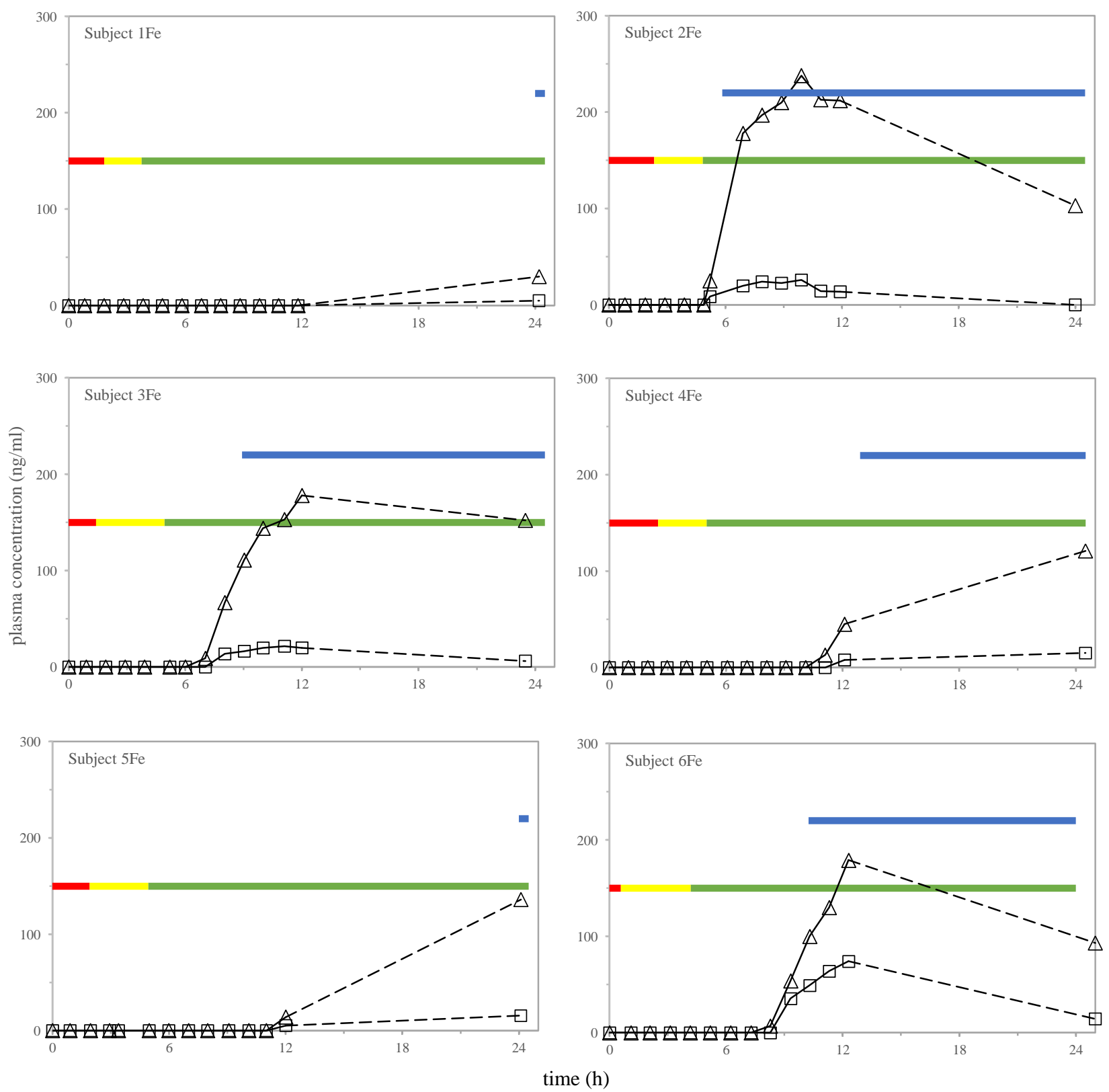

Fig. 8. 5-ASA ( $\square$ ) and Ac5-ASA ( $\Delta$ ) plasma concentrations vs time profiles following administration of the final double-coated system (GM50) to fed volunteers (the dashed portion of the curves indicates the 12-24 h time frame during which no experimental data were collected and does not reflect the actual time course of concentration). Red, yellow and green lines (bottom) indicate gastric, small intestinal and colonic residence, respectively; the blue line (top) indicates disintegration. 
Figure 9 Foppoli et

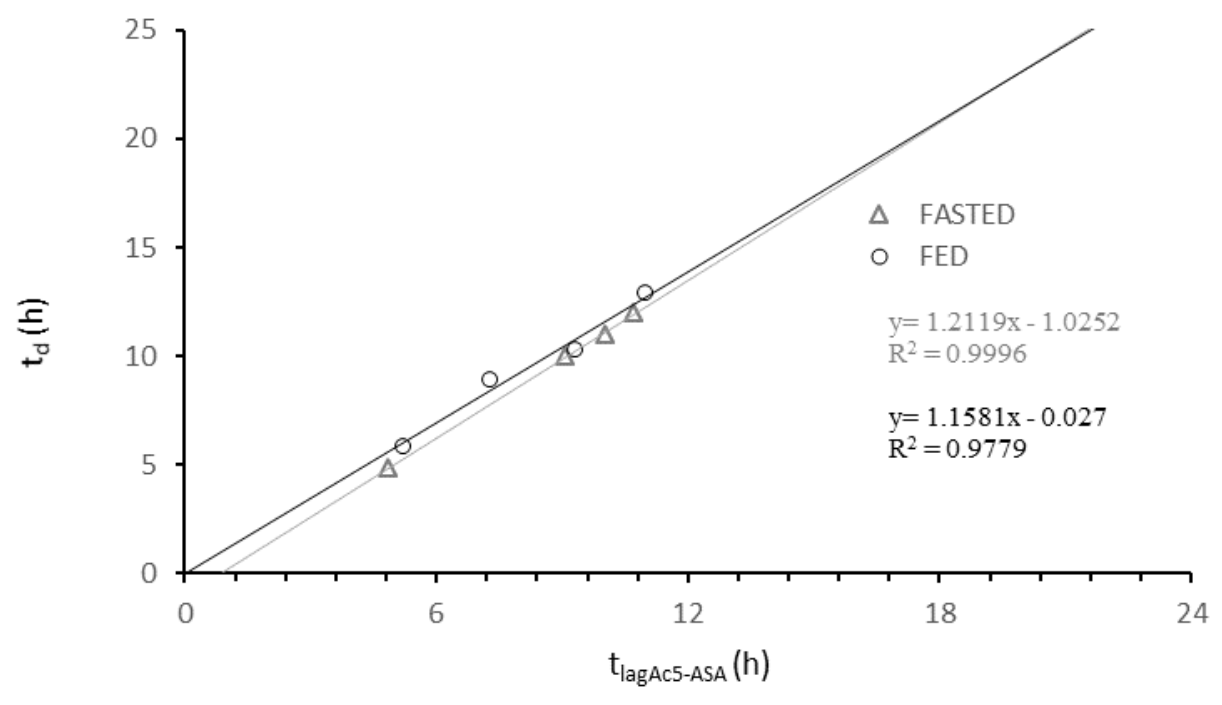

Fig. 9. Relationship between Ac5-ASA in vivo lag time ( $\left.\mathrm{t}_{\text {lagAc5-ASA }}\right)$ and time of disintegration $\left(\mathrm{t}_{\mathrm{d}}\right)$. 